\title{
Peningkatan Hasil Panen Tomat di Desa Sambirejo Dengan Penerapan Teknologi "Sonic Bloom"
}

\author{
Refpo Rahman*1, M. Adeng Fadila ${ }^{2}$, Helfi Eka Saputra ${ }^{3}$, Ridha Rizki \\ Novanda $^{4}$, Umi Salamah $^{5}$, Ahmad Syarkowi ${ }^{6}$, Kiky Nurfitri Sari ${ }^{7}$, Andika \\ Prawanto $^{8}$ \\ ${ }^{1,23456}$ Universitas Bengkulu \\ ${ }^{78}$ Akademi Komunitas Rejang Lebong \\ E-mail: refporahman@unib.ac.id
}

\begin{tabular}{ll}
\hline Article History: & Kata Kunci : \\
Received: Oktober & Desa Sambirejo merupakan salah satu \\
Revised: November & sentra produksi tanaman tomat. Pengaruh \\
Accepted: Desember & cuaca saat ini memberikan dampak yang \\
Available online: & buruk terhadap hasil produksi tomat. \\
Desember & Karena tanaman tomat merupakan \\
& tanaman yang mudah diserang penyakit \\
& sehingga hasil panennya mengalami \\
Kata Kunci: Carlson, & fluktuatif. Melalui penerapan teknologi \\
frequency, Sambirejo, & sonic bloom dapat menambah pengetahuan, \\
Solanum Lycopersicum, & dan keterampilan serta dapat menjadi solusi \\
Sonic bloom, Stoma, & pemecahan masalah dalam meningkatkan \\
Tibicen Linnei & hasil panen petani. Teknologi sonic bloom \\
& merupakan gelombang suara berfrekuensi \\
& 3.500 - 5.000 Hz. Gelombang tersebut dapat \\
& merangsang pembukaan stomata tanaman \\
& sehingga penyerapan pupuk daun meningkat. \\
& Penerapan teknologi ini dapat meningkatkan \\
& produktivitas tanaman tomat yang lebih baik. \\
& Hasilnya batang lebih tinggi, buah jauh lebih \\
& besar dan jumlah buah tomat lebih banyak \\
& dibandingkan dengan tanaman tomat jauh dari \\
& sumber suara.
\end{tabular}




\section{Pendahuluan}

Menurut data Badan Pusat Statistik Kab. Rejang Lebong (2020), luas panen dan produksi tanaman tomat di wilayah ini sekitar 512 Ha dan produksi terbesar kedua dibandingkan dengan jenis sayuran lain yang ada di Kecamatan Selupu Rejang. Desa Sambirejo merupakan salah satu wilayah yang berkontribusi memproduksi tanaman tomat. Menurut petani sekitar, mereka sering mengeluh ketika sedang menanam tomat karena hasil produksi yang kurang baik saat cuaca tidak menentu. Karena tanaman tomat merupakan tanaman yang mudah diserang penyakit sehingga hasil panennya mengalami fluktuatif dan tidak bisa memenuhi permintaan pasar yang besar. Hal ini menjadi permasalahan yang harus diselesaikan untuk menstabilkan produksi tomat dan meningkatkan hasil produksi tomat terutama di desa Sambirejo.

Guna meningkatkan hasil panen tomat diperlukan teknologi baru untuk meningkatkan hasil panen tomat. Teknologi yang diterapkan yaitu sonic bloom. Teknologi sonic bloom merupakan teknologi gelombang suara berfrekuensi $3.500-5.000 \mathrm{~Hz}$ yang di kenalkan oleh Dan Carlson (Suryadarma dkk., 2020). Gelombang suara diberikan pada tanaman untuk merangsang stomata terbuka semakin lebar sehingga meningkatkan efisiensi penyerapan pupuk daun yang sangat berguna bagi tanaman (Istirochah dan Sugiarto, 2017). Hasil penerapan teknologi sonic bloom dapat meningkatkan pertumbuhan, produktivitas dan hasil panen tanaman. Gelombang suara yang digunakan pada kegiatan ini adalah suara alami dari garengpung (Tibicen Linnei). Suara alami binatang digunakan sebagai stimulus pertumbuhan dan produktivitas tanaman (Kadarisman dkk., 2019)

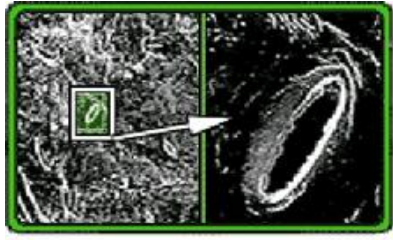

Untreated Stoma

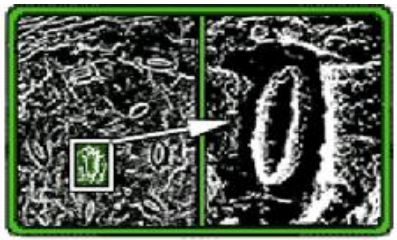

Treated with Sonic Bloom

Gambar 1. Hasil Photomicrographs stomata terbuka lebih lebar dengan frekuensi Carlson

Sumber: Hasil Photomicrographs stomata. Diakses melalui http://dancarlsonsonicbloom.com/About.html\#bio, 27 Maret 2020. 
Teknologi ini akan mendapatkan hasil maksimal, ketika diterapkan saat proses pemupukan. Berdasarkan hasil (Weinberger dan Measures, 2011) bahwa perlakuan intensitas bunyi $92 \mathrm{~dB}$ dapat meningkatkan pembukaan stomata, pertumbuhan dan hasil tanaman. Teknologi ini dapat diterapkan pada jenis tanaman termasuk tanaman tomat. Teknologi sonic bloom ini diharapkan menjadi salah satu alternatif untuk meningkatkan pertumbuhan, produktivitas dan hasil panen tomat bagi warga Desa Sambirejo.

\section{Metode}

Program PPM Ilmu Pengetahuan dan Teknologi dan Seni (IPTEKS) ini dilaksanakan dari bulan Juli hingga Oktober 2020 di Desa Sambirejo menggunakan metode penyuluhan, pelatihan dan pendampingan dalam penerapan teknologi sonic bloom. Tanaman tomat yang diberikan perlakuan sonic bloom adalah tanaman yang berusia sekitar 2 minggu yang ditanam di lahan yang memiliki luas sekitar 10 x $12 \mathrm{~m}$.

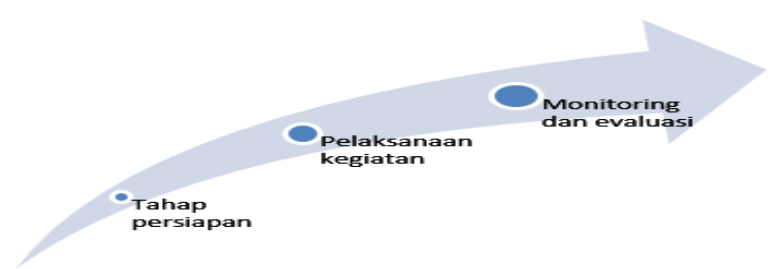

Gambar 2. Alur metode pendekatan penerapan PPM IPTEK

Adapun metode pendekatan yang digunakan dalam kegiatan PPM berbasis IPTEK antara lain:

1. Tahap Persiapan

Tahap persiapan dilakukan dengan koordinasi terlebih dahulu dengan tim LPPM dan khalayak sasaran di Desa Sambirejo. Kemudian melakukan pengurusan perizinan ke mitra di Desa Sambirejo, Kec. Selupu Rejang, Kab. Rejang Lebong, Bengkulu disertai dengan penyusunan rencana dan jadwal pelaksanaan kegiatan pengabdian masyarakat berbasis IPTEK.

2. Pelaksanaan kegiatan

a. Sosialisasi jadwal dan materi kegiatan di lokasi pengabdian 
Sosialisasi merupakan kegiatan awal yang dilakukan dengan memberikan rincian kegiatan yang akan dilaksanakan mulai dari jadwal hingga tahapan pelaksanaan kegiatan.

b. Pengumpulan alat dan bahan pembuatan teknologi sonic bloom.

Peralatan yang digunakan antara lain: box speaker, sound aktif sebagai sumber gelombang suara, aki, kabel, sound level meter, keranjang, chamber dan timbangan. Bahan-bahan yang digunakan yaitu lahan tanam tomat dan pupuk organik (semprot).

c. Pendidikan dan pelatihan di lokasi pengabdian

Pendidikan dilakukan dengan memberikan pengenalan teknologi sonic bloom tentang latar belakang, tujuan, manfaat, dampak, teknik, kendala dan peluang keberhasilan menerapkan teknologi ini. Pelatihan dilakukan dengan menerapkan teknologi ini di lahan tomat.

d. Pendampingan dalam menerapkan teknologi di lahan pertanian.

Khalayak sasaran diberi pendampingan dalam menggunakan teknologi ini seperti teknik pembuatan teknologi sonic bloom, teknik pemeliharaan yaitu menghidupkan gelombang suara dipagi hari dari jam 08.00-09.00 selama satu jam. Agar penerapan teknologi ini dilakukan kontinu oleh masyarakat, dilakukan kontrol secara berkala dengan terus berkomunikasi dengan petani.

\section{Monitoring dan Evaluasi}

Monitoring kegiatan pengabdian ini dilakukan secara harian, mingguan dan bulanan. Monitoring harian dilakukan untuk memastikan teknologi diterapkan saat pemberian pupuk. Monitoring mingguan dilakukan untuk mengetahui perkembangan tanaman budidaya tomat dan hasil buah yang dihasilkan. Monitoring bulanan dilakukan untuk melihat hasil panen buah tomat dan menentukan waktu yang tepat memanen.

\section{Hasil}

Program PPM IPTEKS tentang penerapan teknologi "sonic bloom" di desa Sambirejo. Adapun hasil dan capaian pengabdian yang telah dilaksanakan antara lain, 
1. Sosialisasi pengenalan teknologi "sonic bloom"

Sosialisasi pengenalan teknologi sonic bloom ini telah dilakukan di Desa Sambirejo untuk memberikan pendidikan dan pengetahuan kepada petani. Terlebih dahulu petani di berikan soal pre-test tentang sonic bloom. Hasil pretest menunjukkan bahwa kelompok tani Desa Sambirejo belum mengetahui teknologi sonic bloom sebelumnya dan petani memiliki antusias yang tinggi untuk belajar dan menerapkan ke lahan yang mereka miliki masing-masing.

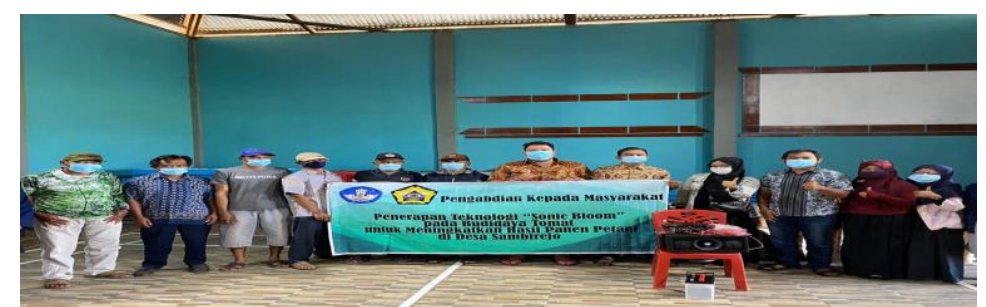

Gambar 3. Sosialisasi pengenalan teknologi sonic bloom di balai Desa Sambirejo

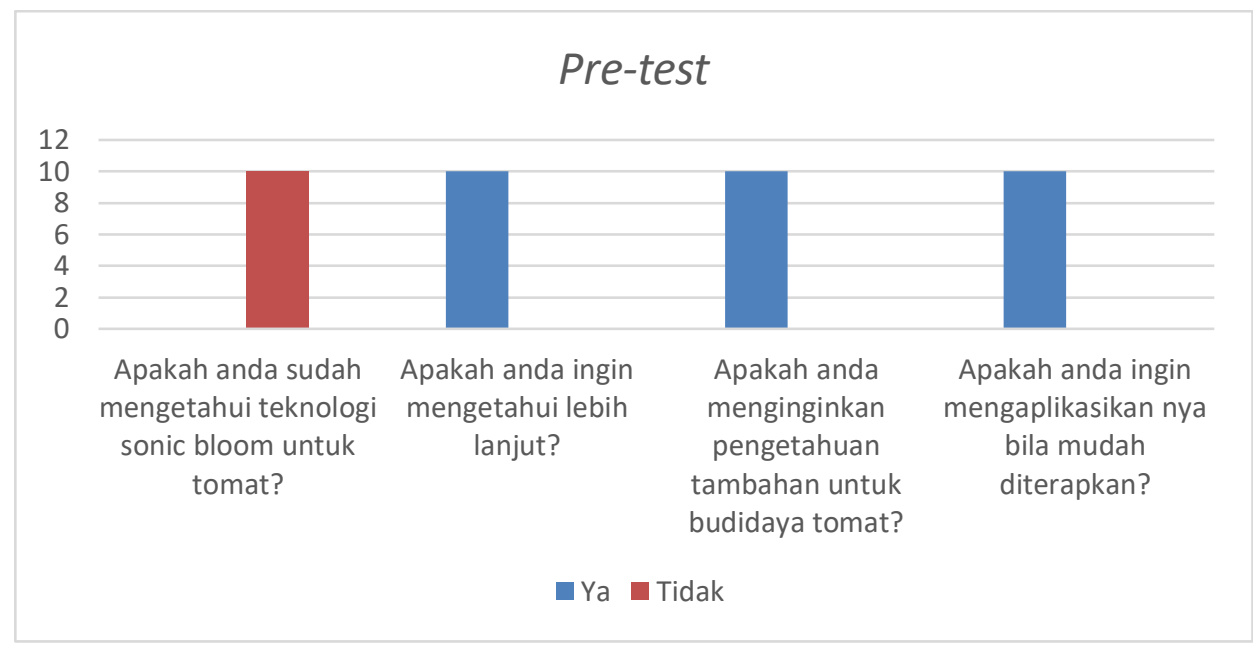

Gambar 4. Hasil pre-test dari kegiatan sosialisasi

Setelah disosialisasikan, petani diberikan soal post-test. Hasil post-test menunjukkan bahwa kelompok tani Desa Sambirejo sudah memahami teknologi sonic bloom dan memiliki keinginan untuk menerapkan teknologi ini. 


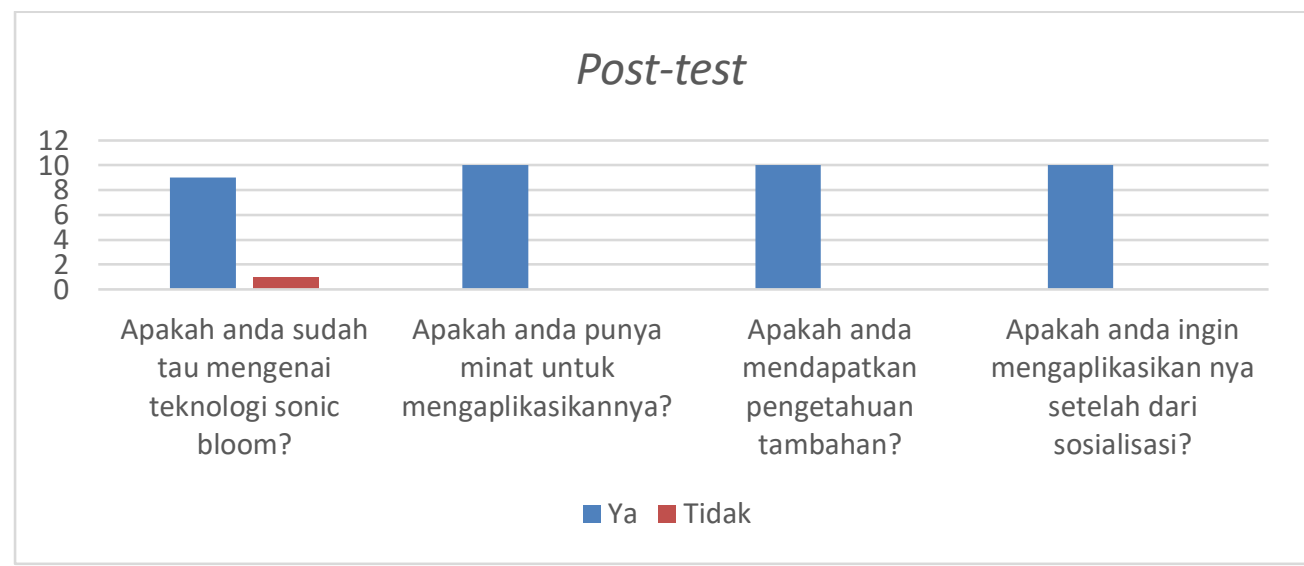

Gambar 5. Hasil post-test dari kegiatan sosialisasi

2. Pelatihan merangkai alat dan bahan teknologi "sonic bloom".

Pada tahapan ini, kelompok tani Desa Sambirejo diberikan pendidikan, pelatihan dan merakit alat teknologi sonic bloom yang diterapkan di lahan tomat. Adapun alat yang digunakan antara lain speaker rakitan, box speaker, amplifier (penguat suara), aki mobil (sumber listrik) dan kabel. Sedangkan, bahan yang digunakan pada kegiatan ini adalah pupuk cair untuk mendukung keberhasilan teknologi ini.

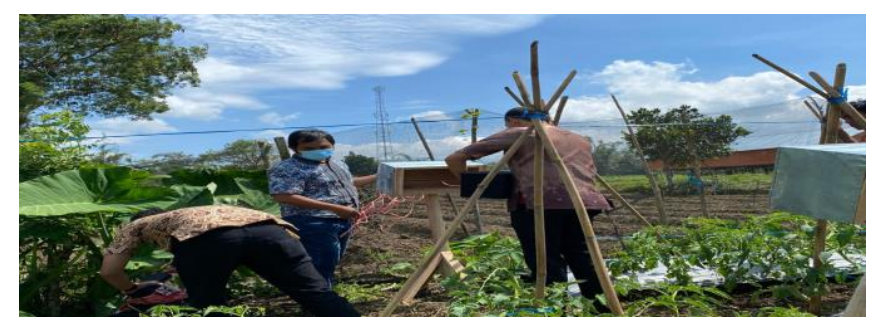

Gambar 6. Pelatihan merancang dan penerapan alat sonic bloom

3. Pendampingan penerapan teknologi "sonic bloom"

Pada tahapan ini, setelah alat yang telah dirangkai ditempatkan dilahan tani perlu adanya pendampingan agar hasil yang dicapai terhadap tanaman sesuai yang diharapkan. Hasil diperoleh bahwa tanaman di sekitar gelombang suara memiliki perubahan dari batang yang lebih tinggi, buah yang besar dan lebih banyak dibandingkan dengan tomat jauh dari sumber suara. Hal ini 
sesuai dengan hasil penelitian (Murni N, Achayani Dan Santoso H, 2018) bahwa perlakuan variasi amplitude $(\mathrm{dB})$ dengan gelombang suara single tone memberikan pengaruh signifikan terhadap pertumbuhan panjang batang, lebar daun pada daun kecambah tomat.

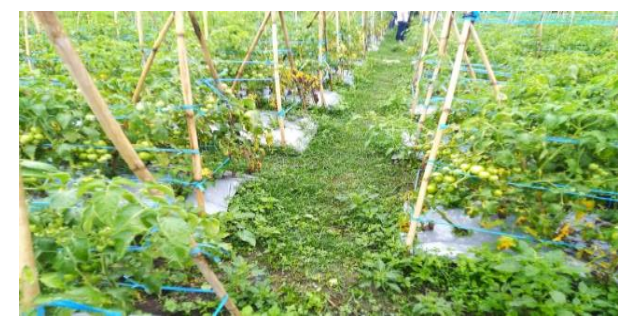

(a)

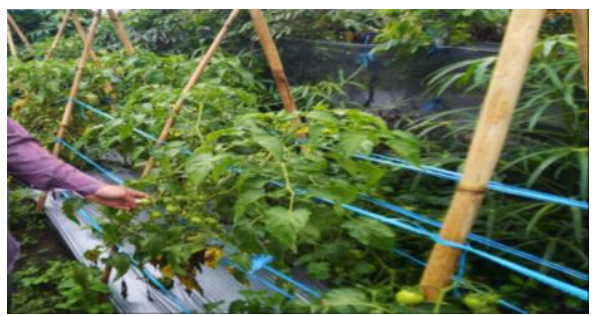

(b)

Gambar 7. Hasil buah tanaman tomat (a) dekat sonic bloom dan (b) jauh dari sonic bloom

4. Monitoring dan Evaluasi

Pada tahapan ini, tim LPPM UNIB memantau kegiatan tim PPM IPTEKS di Desa Sambirejo. Tim LPPM menerima informasi dari petani bahwa terjadi peningkatan jumlah buah dan ukuran buah yang besar serta tanaman yang lebih tinggi di sekitar sumber suara. Hasil ini juga memberikan evaluasi kepada tim PPM untuk lebih banyak berkontribusi pada teknologi pertanian untuk meningkatkan hasil produksi serta meningkatkan produktivitas tanaman.

\section{Diskusi}

Teknologi yang diterapkan pada kegiatan ini adalah teknologi sonic bloom dengan memanfaatkan frekuensi gelombang suara sekitar 4000-5000 $\mathrm{Hz}$ yang diberikan kearah tanaman (Carlson, 1941). Pemanfaatan gelombang suara dengan frekuensi tinggi dapat memicu terbukanya mulut daun (stomata) dan mempengaruhi gerakan karbondioksida $\left(\mathrm{CO}_{2}\right)$ di sekitar tanaman yang mempengaruhi penyerapan karbondiosida menjadi lebih baik. Terbuka lebarnya stomata daun dapat meningkatkan nutrisi tanaman / proses fotosintesis (Prasetyo dan Lazuardi, 2017). 
Penerapan teknologi ini di usia awal untuk mengetahui perkembangan tomat dari awal hingga masa panen. Keberhasilan budidaya tomat dengan menerapkan sonic bloom harus memperhatikan beberapa aspek lainnya seperti nutrisi dan unsur hara pada tamanan. Teknologi sonic bloom ini hanya merangsang tanaman untuk terbukanya stomata lebih lebar dibandingkan tanpa perlakuan. Karena tanpa nutrisi pupuk yang baik, tanaman tidak akan berkembang dan tumbuh subur. Penggunaan pupuk yang baik menyebabkan nutrisi lebih cepat diserap oleh tanaman (Istirochah dan Sugiarto, 2017)

Tahapan-tahapan pelaksanaan kegiatan dilakukan secara terstruktur antara lain, 1) sosialisasi pengenalan teknologi sonic bloom, 2) pelatihan merangkai alat dan bahan dari teknologi sonic bloom, dan 3) pendampingan penerapan teknologi sonic bloom. Tahapan awal, sosialisasi teknologi sonic bloom dilakukan dibalai desa berdasarkan hasil pre-test dan post-test yang telah diberikan bahwa petani di desa Sambirejo sangat antusias untuk mengikuti kegiatan dan memiliki minat yang tinggi untuk menerapkan teknologi ini di lahan pertanian yang dimiliki. Teknologi ini tidak hanya dapat diterapkan pada tanaman tomat melainkan juga pada jenis tanaman lainnya.

Tahap kedua, alat dan bahan yang digunakan pada kegiatan ini antara lain, speaker rakitan, amplifier, aki dan kabel. Serta bahan yang digunakan adalah pupuk daun yang nantinya disemprot ke daun. Dari informasi ini, alat dan bahan yang digunakan bukanlah alat yang sulit untuk ditemui ataupun untuk dibeli. Karena petani pun juga sudah memiliki alat tersebut seperti speaker. Namun untuk di lapangan luas tidak bisa digunakan karena banyak lahan pertanian yang tidak ada sumber listrik PLN. Sehingga, dari tim PPM memberikan solusi dengan memberikan contoh penggunaan aki mobil sebagai alternatif sumber listrik. Agar hasil penerapan teknologi ini maksimal, alat ditempatkan di sudut dengan memberikan gelombang suara sekitar $5000 \mathrm{~Hz}$ dengan intensitas level suara sekitar $80 \mathrm{~dB}$ yang diukur menggunakan sound level meter. Suara yang digunakan pada teknologi ini adalah suara garengpung yang peak frekuensinya dikecilkan menjadi $5000 \mathrm{~Hz}$. Perlakukan Sonic bloom ini di pagi hari sekitar jam 07.00 - 08.00, dengan 30 menit pertama tanpa pemupukan dan 30 menit akhir proses pemupukan. Hal ini dilakukan agar pupuk yang disemprot setelah diberikan gelombang suara akan mempercepat 
nutrisi yang masuk lewat stomata daun.

Tahap ketiga, pendampingan terhadap perlakuan sonic bloom. Pendampingan yang telah dilakukan pada petani tomat memberikan hasil yang sangat baik terhadap tanaman tomat. Petani menjelaskan bahwa telah melakukan pemupukan kurang lebih 20 kali pemupukan dalam kurun waktu 2 bulan hingga masa panen. Berdasarkan pengamatan petani, tanaman tomat mengalami perubahan yang signifikan, khususnya tanaman yang berada didekat gelombang suara. Petani yang mengontrol tanaman tomat menjelaskan bahwa batang di sekitar sumber suara berukuran lebih tinggi dan buah yang dihasilkan lebih banyak dan berukuran besar dibandingkan dengan tanaman tomat yang jauh dari sumber bunyi. Sehingga, hasil panen petani mengalami peningkatan dibandingkan dengan hasil panen tomat terdahulu. Hal ini sesuai dengan perhitungan yang telah dilakukan pada penelitian sebelumnya bahwa teknologi sonic bloom akan menyebabkan tanaman menjadi lebih tinggi, daun lebih lebar dan hasil buah yang lebih banyak (Sutan, Joko dan Imam, 2018), (Prasetyo, Mandang, dan Subrata., 2014), (Rosana dkk., 2017), (Afifah dkk., 2015). Dampak dari kegiatan ini, petani antusias untuk menerapkan teknologi sonic bloom pada tanaman lain karena memberikan hasil yang sangat baik.

\section{Kesimpulan}

Masyarakat memiliki antusiasme yang tinggi terhadap teknologi tepat guna ini. Dari hasil sosialisasi, perancangan alat dan bahan, pendampingan kegiatan dan monitoring evaluasi bahwa petani di Desa Sambirejo memiliki peningkatan pengetahuan dan tingkat inovatif masyarakat tentang teknologi tepat guna "sonic bloom" yang dapat meningkatkan produktivitas dan hasil panen. Metode penyampaian informasi dan praktek langsung dinilai efektif dalam program ini dilihat dari berhasilnya teknologi sonic bloom ini bagi petani. Karena dapat meningkatkan kualitas tanaman dengan ukuran tanaman yang lebih tinggi dan buah yang lebih banyak serta ukuran yang lebih besar. Teknologi ini juga mejadi harapan besar bagi petani karena dapat diterapkan ke berbagai jenis tanaman lainnya.

\section{Pengakuan/Acknowledgements}

Terimakasih kepada LPPM Universitas Bengkulu atas financial 
support (no kontrak: 2370/UN30.15/AM/2020) untuk Pengabdian pada masyarakat (PPM) IPTEKS. Terimakasih kepada Desa Sambirejo atas kesempatan serta kerjasamanya sehingga PPM IPTEKS dapat dilaksanakan dengan baik.

\section{Daftar Referensi}

Afifah, E., Nugrahani, M., Prasetyo, N., Berlian, I., Rinojati, N., \& Kadarisman, N. (2015). Utilization of Audio Bioha rmony to Improve Rubber (Hevea brasiliensis) Growth in the Nursery. Current Agriculture Research Journal, 3(1), 01-06. https://doi.org/10.12944/carj.3.1.01

Carlson, D. (2020). The Sonic Bloom Growing System. Http://Dancarlsonsonicbloom.Com/. Diakses pada tanggal 27 Maret 2020

Istirochah, P., \& Sugiarto. (2017). Pengaruh intensitas bunyi terhadap pembukaan stomata , pertumbuhan dan hasil kedelai ( Glycine Max ( L .) Merril ) melalui aplikasi sonic bloom. Jurnal Folium, 1(1), 60-70.

Kadarisman, N., Agustika, D. K., Purwanto, A., Alvianty, V., \& Wibowo, B. (2019). Characterization of Sound Spectrum based on Natural Animals as an Alternative Source of Harmonic System Audio Bio Stimulators for Increasing Productivity of Food Plants. Journal of Physics: Conference Series, 1387(1). https://doi.org/10.1088/1742-6596/1387/1/012098

Murni, N., Achyani, A., \& Santoso, H. (2018). Pengaruh amplitude sonic bloom single tone terhadap perkecambahan benih tomat cherry (Lycopersicum cerasiforme Mill). BIOEDUKASI (Jurnal Pendidikan Biologi), 9(2), 154-165.

Prasetyo, J., \& Lazuardi, I. B. (2017). Pemaparan Teknologi Sonic Bloom Dengan Pemanfaatan Jenis MusikTerhadap Pertumbuhan Vegetatif Tanaman Selada Krop ( Lactuca Sativa L ). Jurnal Keteknikan Tropis Dan Biosistem, 5(2), 189-199.

Prasetyo, J., Mandang, T., \& Subrata, I. (2014). Efek Paparan Musik dan Noise pada Karakteristik Morfologi dan Produktivitas Tanaman Sawi Hijau (Brassica Juncea). Jurnal Keteknikan Pertanian, 2(1), 21959.

Rosana, D., Kadarisman, N., Maryanto, A., \& Sugiharsono, A. (2017). The evaluation of science learning program, technology and society application of Audio Bio Harmonic System with solar energy to improve 
crop productivity. Jurnal Pendidikan IPA Indonesia, 6(1), 63-70. https://doi.org/10.15294/jpii.v6i1.9596

Suryadarma, I. G. P., Widiastuti, Nur Kadarisman, \& Dwandaru, W. S. B. (2020). the Increase of Stomata Opening Area in Corn Plant Stimulated By Dundubia Manifera Insect Sound. International Journal of Engineering Technologies and Management Research, 6(5), 107-116. https://doi.org/10.29121/ijetmr.v6.i5.2019.377

Sutan, S. M., Prasetyo, J., \& Mahbudi, I. (2018). Pengaruh Paparan Frekuensi Gelombang Bunyi terhadap Fase Vegetatif Pertumbuhan Tanaman Kangkung Darat ( Ipomea Reptans Poir ) The Effect of Exposure Sound Waves Frequency on Plant Growth Vegetative Phase of Kale ( Ipomea Reptans Poir ). Jurnal Keteknikan Pertanian Tropis Dan Biosistem, 6(1), 72-78.

Weinberger, P., \& Measures, M. (2011). Effects of the intensity of audible sound on the growth and development of Rideau winter wheat. Canadian Journal of Botany, 57, 1036-1039. 